\title{
BMJ Open U-Flourish university students well- being and academic success longitudinal study: a study protocol
}

\author{
Sarah Margaret Goodday, ${ }^{1}$ Daniel Rivera, ${ }^{2}$ Hannah Foran, ${ }^{2}$ Nathan King, ${ }^{3}$ \\ Melissa Milanovic, ${ }^{4}$ Charles DG Keown-Stoneman, ${ }^{\oplus 5}$ Julie Horrocks, ${ }^{6}$ \\ Elizabeth Tetzlaff, ${ }^{7}$ Christopher R Bowie, ${ }^{4}$ William Pickett, ${ }^{3}$ Kate Harkness, ${ }^{4}$ \\ Kate E Saunders, ${ }^{8}$ Simone Cunningham, ${ }^{4}$ Steven McNevin, ${ }^{9}$ Anne Duffy ${ }^{\circ}$
}

To cite: Goodday SM, Rivera D, Foran $\mathrm{H}$, et al. U-Flourish university students well-being and academic success longitudinal study: a study protocol. BMJ Open 2019;9:e029854. doi:10.1136/ bmjopen-2019-029854

- Prepublication history and additional material for this paper are available online. To view these files, please visit the journal online (http://dx.doi. org/10.1136bmjopen-2019029854).

Received 26 February 2019 Revised 23 July 2019 Accepted 30 July 2019
Check for updates

(C) Author(s) (or their employer(s)) 2019. Re-use permitted under CC BY-NC. No commercial re-use. See rights and permissions. Published by BMJ.

For numbered affiliations see end of article.

Correspondence to

Dr Anne Duffy;

anne.duffy@queensu.ca

\section{ABSTRACT}

Introduction Over $30 \%$ of Canadians between the ages of 16 and 24 years attend university. This period of life coincides with the onset of common mental illnesses. Yet, data to inform university-based mental health prevention and early intervention initiatives are limited. The U-Flourish Iongitudinal study based out of Queen's University, Canada and involving Oxford University in the UK, is a student informed study funded by the Canadian Institute for Health Research Strategy for Patient Oriented Research (CIHR-SPOR). The primary goal of U-Flourish research is to examine the contribution of risk and resiliency factors to outcomes of well-being and academic success in first year students transitioning to university.

Methods and analysis The study is a longitudinal survey of all first-year undergraduate students entering Queen's University in the fall term of 2018 (and will launch at Oxford University in fall of 2019). In accordance with the CIHR-SPOR definitions, students represent the target population (ie, patient equivalent). Student peer health educators were recruited to inform the design, content and implementation of the study. Baseline surveys of Queen's first year students were completed in the fall of 2018, and follow-up surveys at the end of first year in the spring of 2019. Extensive student-led engagement campaigns were used to maximise participation rates. The baseline survey included measures of personal factors, family factors, environmental factors, psychological and emotional health, and lifestyle factors. Main outcomes include self-reported indicators of mental health at follow-up and mental health service access, as well as objective measures of academic success through linkage to university administrative and academic databases. A combination of mixed effects regression techniques will be employed to determine associations between baseline predictive factors and mental health and academic outcomes.

Ethics and dissemination Ethical approval was obtained by the Health Sciences and Affiliated Teaching Hospitals Research Ethics Board (HSREB) (\#6023126) at Queen's University. Findings will be disseminated through international and national peer-reviewed scientific articles and other channels including student-driven support and advocacy groups, newsletters and social media.

\section{Strengths and limitations of this study}

Collaboration with students at all stages of the research process.

- A strong student-led engagement campaign resulted in a participation rate of almost $60 \%$ of the entire first-year undergraduate student body at Queen's University.

- Findings will inform universal and targeted prevention and early intervention initiatives.

- Comparison of findings across universities (Queen's and Oxford) will be forthcoming

\section{INTRODUCTION}

The transition to university life coincides with a critical time in psychosocial and biological development. At the same time, the brain is undergoing accelerated growth and has increased sensitivity to risk exposures such as perceived stress, substance use and sleep problems. ${ }^{1}$ Not surprisingly, the developmental period from 16 to 24 years of age represents a peak period of risk for the onset of psychiatric illness. ${ }^{1-3}$ Universities have an obligation to provide resources to support student well-being and academic success during this critical transitional period. Yet, there is limited evidence to inform universities as to how to meet the spectrum of need, which ranges from resiliency building and health promotion to supporting students experiencing transient distress and identifying those with emergent psychiatric illness who require referral to specialty services. ${ }^{4}$

Approximately 1.7 million students were enrolled in universities across Canada in $2017 .^{5}$ The age at university entry in Canada has been declining since 1980 and the proportion of international compared with domestic students has been increasing, translating 
into a sizeable population of students from varied backgrounds with diverse risk and resiliency profiles. ${ }^{6}$

A recent cross-sectional survey of first-year students at Queen's University found that $28 \%$ self-identified as having a mental illness, over $30 \%$ engaged in binge drinking and almost $20 \%$ used cannabis within the past 2 weeks. ${ }^{7}$ In the same survey, the top ranked reasons reported by students for lower grades in a pivotal assignment or exam were related to mental health including: stress $43 \%$, sleep problems $29 \%$, anxiety $26 \%$ and depression $15 \%$. The nationally representative Canadian Health Behaviour in School-Aged Children Study reported findings consistent with this trend, and that poor interpersonal relationships with parents and peers and unhealthy lifestyles behaviours reflect important contributors to mental health problems. ${ }^{8}$

Family factors have been associated with mental health and academic outcomes in students. Specifically, a history of mental illness in first-degree relatives is a major risk factor for emerging mental illness in youth. ${ }^{9}{ }^{10}$ Current models suggest the risk of mental illness in youth is in part caused by an interaction between genetic predisposition and experience of early adversity (eg, childhood abuse), early life stress, and trauma, compounded by more proximal risk exposures, such as peer support and social connectedness, perceived stress and substance use. ${ }^{11-13}$ Evidence supports that parental attitudes also influence student well-being and academic success. ${ }^{14}$ For example, a student's perception of parental beliefs shapes their assessment of how appropriate and achievable their academic goals are. In addition, students who perceive greater parental warmth appear to work harder to pursue their academic goals and believe more strongly in reward based on merit (ie, internal locus of control), all of which contribute to better academic outcomes. ${ }^{14} 15$

University students commonly experience a variety of environmental stressors across financial, academic and social domains. ${ }^{16}$ While many stressed students do not develop severe or persistent mental illness, perceived stress is associated with distressing depressive and anxiety symptoms which in turn impact academic performance. ${ }^{16}$ The most commonly reported stress in university students has to do with social relationships. ${ }^{18}$ Transition to university comes at a time of disrupted and vulnerable social support networks. A higher quality of reported peer relationships is positively associated with self-esteem, emotional well-being and academic success. ${ }^{19-21}$ Social isolation in one study was the strongest overall predictor of emotional distress, while assessment stress was the strongest predictor of academic outcomes. Furthermore, a student's sense of belonging to and identification with the university they attend has been associated with both well-being, life satisfaction and academic performance. ${ }^{1522}$

Several psychological characteristics are associated with academic achievement in university students. Motivation is defined in terms of student valuation of their education and assessed by measuring the importance of succeeding, the interest and enjoyment of the task, the goodness of fit with individual goals and the amount of perceived effort needed to succeed. ${ }^{15}$ Expectancy beliefs are also important to academic success and have been assessed through self-efficacy, locus of control and perceived competence. ${ }^{23}{ }^{24}$ Specifically, it appears that students are more likely to set higher academic goals and feel more motivated to achieve these goals when they believe success is based on their own effort and that they are competent to achieve these goals. The literature also supports that student ability to self-regulate sleep and study habits are important contributors to academic success. ${ }^{25} 26$

We currently lack adequate data on the collective contribution of risk factors to mental health and academic outcomes in students transitioning to university. We therefore launched the U-Flourish study—a longitudinal study of all incoming first-year undergraduate students, and those entering first-year professional schools of law and medicine. The aim of the research is to understand why some university students flourish and others do not in the transition to university life in terms of their academic and mental health outcomes. Specific objectives include to:

1. Partner with students in research to improve mental health and academic outcomes.

2. Describe the mental health needs of university students.

3. Identify risk and resiliency profiles pertaining to student outcomes.

4. Determine the individual and collective contribution of family, personal and environmental factors on outcomes of well-being and academic success in university students to inform resource and service development.

5. Understand the longitudinal relationship between mental health and academic outcomes.

\section{METHODS AND ANALYSIS}

\section{Patient and public involvement}

This is a student-informed research effort. Peer health educators (PHEs) are included at all stages of the research from design to implementation and we will include the student perspective in the interpretation and dissemination of findings.

\section{Setting}

The U-Flourish Survey is a longitudinal study based at Queen's Universityin Kingston, Ontario, Canada (https:/ / www.queensu.ca/about/). Queen's is a public undergraduate education-intensive university founded in 1841 via a Royal Charter issued by Queen Victoria. The majority of its almost 19000 undergraduate students currently come from surrounding major cities in Canada (eg, Toronto, Ottawa and Montreal) and regions across the province of Ontario, with a lesser number of students coming from other provinces in the country. The proportion of international students is increasing but remains around $10 \%$ of the undergraduate student body. The majority (over 85\%) of first-year students entering Queen's live in 


\section{Student Engagement* U-Flourish Study}

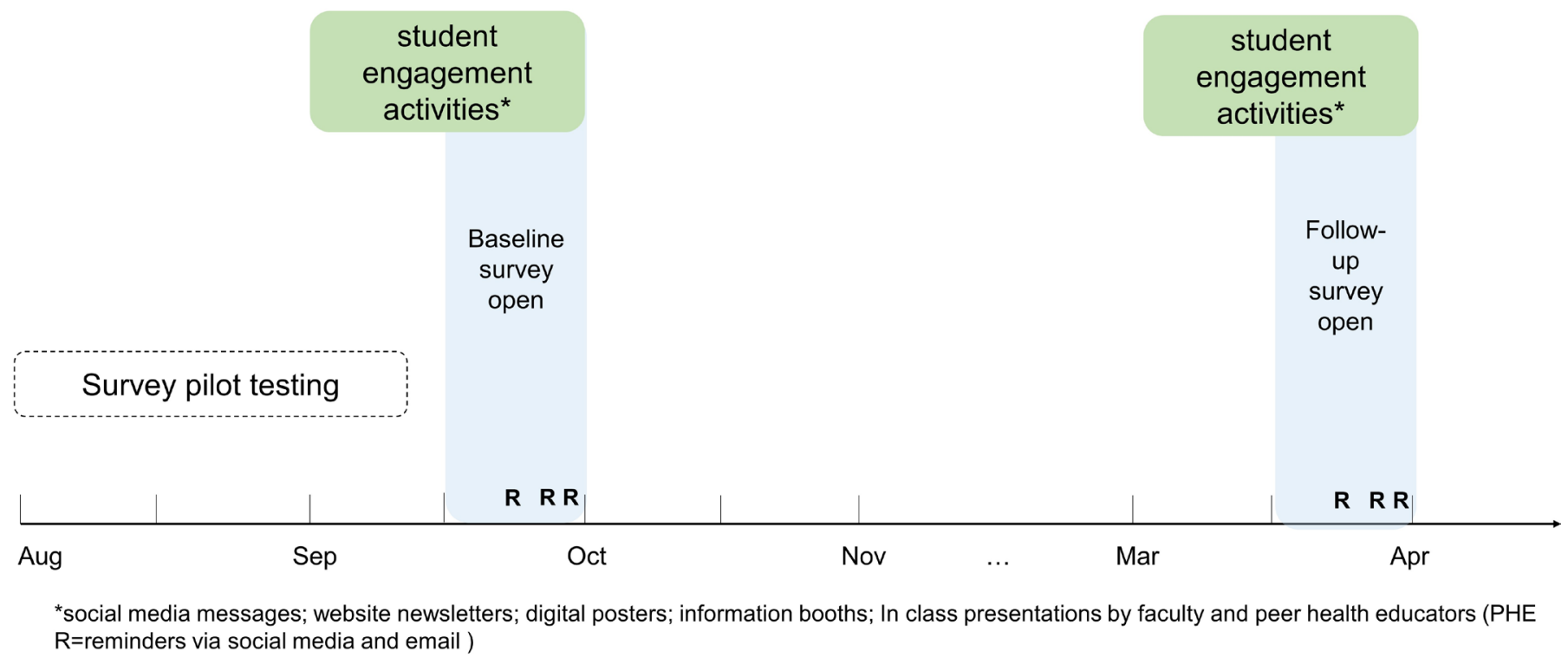

Figure 1 Study design and timing of engagement activities, survey launches and email reminders (R).

residence on campus. The U-Flourish study will launch at a partner site, Oxford University in the fall of 2019. This will allow comparison across two different universities, both with high rates of students living in college.

\section{Target population and stakeholder involvement}

The Canadian Institutes for Health Research Strategy for Patient-Oriented Research initiative defines patients as: 'anyone who has personally lived the experience of a health issue as well as their informal caregivers including family and friends' (http://www.cihr-irsc.gc.ca/e/documents/spor_panel-en.pdf). Under the SPOR theme, students as 'patients' represented the target population for potential interventions that might develop from the research. We included PHEs as key stakeholders to inform the design, content and implementation of the survey.

\section{Procedure}

All first-year students were invited to take part including first-year students entering professional schools of business, medicine and law. Any newly enrolled first-year undergraduate student consenting to the study was eligible to participate. There were no exclusion criteria in order to maximise representativeness of the sample of undergraduate students.

We launched the Queen's University baseline survey approximately 2 weeks into the fall 2018 term (figure 1). We sought to maximise participation through an ambitious student-designed and student-led engagement campaign, creating a study brand and logos now trademarked with the Canadian Government (online supplementary information). While we targeted a minimum participation rate of $30 \%$ for an adequately powered study, we achieved a response rate of $58 \%$ of all first-year Queen's students completing the baseline survey resulting in a cohort 3029 out of a possible 5242 (figure 2). About $64 \%$ of students participating in the baseline survey completed the follow-up survey resulting in a completed 1-year study sample of 1952 students with time 1 and time 2 observations. There were 32 additional students who started but did not complete the time 1 survey but did complete the follow-up time 2 survey putting the total number of students with outcome data to 1984 .

The launch of the baseline survey was announced on each student's e-learning platform (D2L). All first-year students were sent a link to complete the survey via their university email. The portal to complete the survey was open for 2 weeks after the launch. Those completing the survey were credited with $\$ 5$ Flex dollars donated by the University Division of Student Affairs that could be used at campus venues such as a café or dining hall.

The same engagement procedure was used for the follow-up survey. Specifically, 1 month prior to the end of the spring term, a second media and engagement campaign led by the PHEs was launched. Two weeks prior to the end of spring term classes at the end of March, students who opened the link to the baseline study were sent a link via their university email to complete the follow-up survey. The portal remained open for a 2-week period. As an incentive, students completing the time 2 survey were credited with $\$ 5$ Flex dollars again donated by Student Life and offered the opportunity to enter a draw to win 1 of 10 iPads (see below and figure 1). 


\section{U-Flourish}

First-Year Queen's University Student Survey

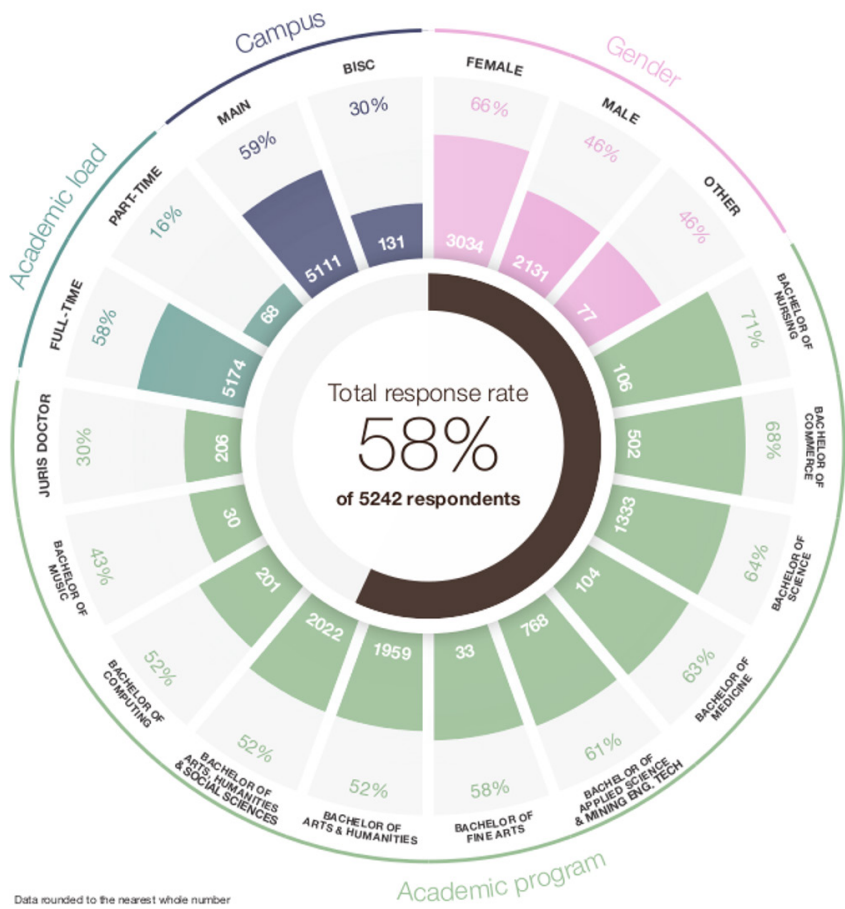

Figure 2 U-Flourish baseline survey response rate and characteristics responding students.

Qualtrics survey software ${ }^{27}$ was used as the electronic platform for the survey. Once students click on the link, they are brought to the introduction page which displays a Letter of Information detailing the name of the study, study funder, investigators and the aims of the research. Drop-down menus and branching logic were used to facilitate the ease of completion of the e-survey. The baseline survey took approximately $12 \mathrm{~min}$ to complete while the follow-up survey took approximately $8 \mathrm{~min}$ to complete.

\section{Student engagement: orientation week}

Student engagement began in the 2018 fall semester orientation week during which student PHEs were present at two separate club fairs and three orientation week presentations run by various faculties. The orientation week presentations were part of the Concurrent Education, Kinesiology and Off-Campus student orientation weeks. The PHEs were able to provide information about the fall baseline survey, answer student questions, and encourage participation to a considerable proportion of the 5242 incoming students.

\section{Student engagement: branding and advertising}

U-Flourish graphics and branding were presented to students and PHEs to determine the most effective for engagement. Print and digital posters (online supplementary information) were placed at various public locations across campus including three dining halls, two student centres and numerous other dining locations on campus prior to and while the survey was open. A messaging campaign was established via the university's social media accounts that released nine distinct posts with information about the survey along with a professionally created and branded graphics similar to the posters placed around the campus (online supplementary information-social media posts). Emphasis was placed on the use of student-centric language and phrases that urged students to 'have their say' and contribute to the conversation about what was needed to support well-being and academic success through partaking in the study. A total of four campus booths were set up during the survey period and staffed by PHEs. At these booths, students were able to show an electronic receipt for completing the baseline survey and receive a free pizza lunch, as well as small branded items such as stress balls and laptop stickers. Students, regardless of status of survey completion, were able to interact with the student PHE's who provided information about the study and its relevance to student life.

\section{Student engagement: in-class presentations}

In the first and second week of classes, 19 in-class talks were given by the study investigators (faculty at the Queen's University) and PHEs targeting the largest firstyear classes in each programme. These presentations included informative slides and a standardised script to share information about the aims of the study (online supplementary information).

\section{Student engagement: incentives}

A $\$ 5$ credit applied to student's accounts was offered to students completing each of the baseline surveys and follow-up surveys. Information on how to earn and access the $\$ 5$ credit was described during in-class presentations and on the websites. In addition, branded postcards announcing the study along with laptop stickers with the U-Flourish logo were distributed in drawstring bags that are given to every incoming student at the beginning of the orientation week. The Division of Student Life at Queen's University provided the $\$ 5$ Flex credit incentive as a donation in kind to the project.

\section{Student engagement: university web-platforms}

The U-Flourish team worked with campus-based film production service and student volunteers to make engaging brief video clips introducing the survey and posted on the first-year student D2L learning platform and U-Flourish study website (http://www. queensu.ca/studentwellness/health-promotion/ u-flourish-student-health-project).

\section{Student engagement: reminders}

A total of three reminder emails were sent to students to participate and redeem their rewards for survey completion 1 week after the survey launch, at the beginning of the second week after the launch, and $48 \mathrm{~h}$ prior to the close of the survey (figure 1). Messages containing important survey information were sent to incoming 
students through programme newsletters, student residence newsletters and the online learning platforms used by large first-year classes (online supplementary information). A message to all respondents was sent out thanking them for their initial participation and wishing them luck with their final examinations. They were also encouraged to participate in the follow-up survey and stay vigilant for updates on the study webpage.

\section{Follow-up survey engagement}

The general procedure and methods used to engage students with the baseline survey were used to re-engage respondents with the study and its follow-up survey that launched in March 2019. In addition, class talks were given to the same full-(two-term) classes in the winter semester by the same presenters. The same social media and messaging channels were used with information specific to the follow-up survey. Reminder emails were also sent to baseline respondents to inform them of on campus events such as the booths with redeemable lunch and branded items. In all messaging, the incentive of a chance to win one of ten iPads and 'a call to action' was emphasised to increase student interest.

\section{Survey measures}

\section{Background literature}

Measures included in the baseline and follow-up survey targeted the assessment of factors hypothesised to contribute to student mental health and academic outcomes. Specifically, measures were chosen on the basis of: (1) the available evidence; (2) their relevance to post-secondary student populations; (3) good psychometric properties (Supp. table 1) and (4) acceptability as judged from PHE and student feedback.

\section{Survey content}

The baseline survey (table 1) included factors from five domains: personal factors (eg, socio-demographic, self-esteem $^{28}$ ) family factors (eg, family intactness (parental marital status) and parental warmth ${ }^{29}$ ) environmental factors (eg, peer-relations ${ }^{30}$ and early adversity ${ }^{31}$ ) psychological and emotional health (eg, anxiety, ${ }^{32}$ depressive symptoms, ${ }^{33}$ suicide-related behaviour ${ }^{34}$ and expectancy beliefs ${ }^{35}$ ) and motivations for learning ${ }^{36}$ and lifestyle habits and behaviour (eg, frequency of alcohol, caffeine consumption and exercise and sleep ${ }^{37}$ ) (see table 1 for measure information).

The follow-up survey (table 2) included measures of mental health such as symptom rating scales of anxiety, ${ }^{32}$

\section{Table 1 Baseline survey contents}

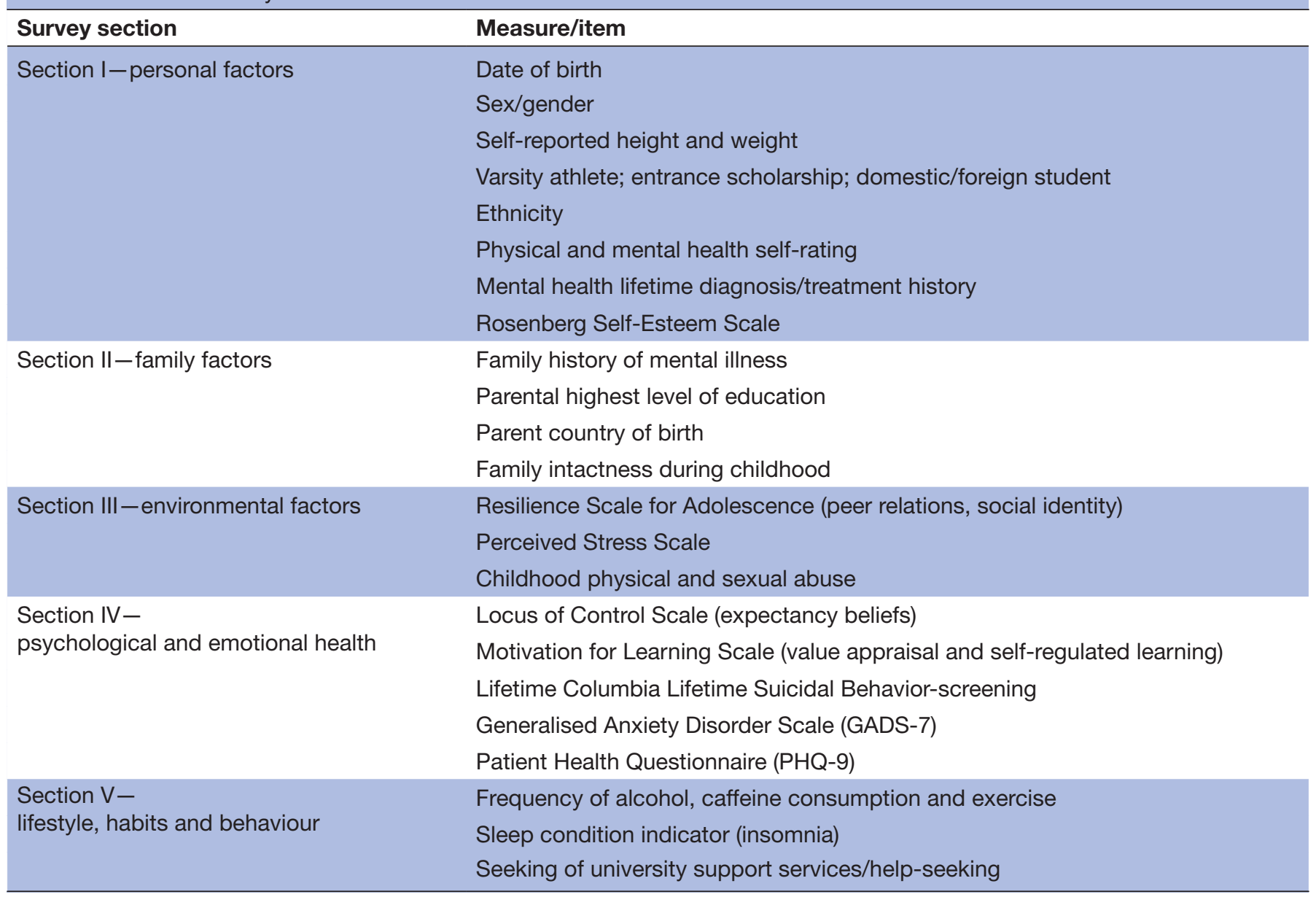


Table 2 Follow-up survey contents

\begin{tabular}{ll}
\hline Survey section & Measure/item \\
\hline Section I-mental health & Mental health new-onset diagnosis/treatment \\
& Patient Health Questionnaire (PHQ-9) \\
& Generalized Anxiety Disorder Scale (GADS-7) \\
& Brief Multidimensional Student's Life Satisfaction Scale \\
& College Student Subjective Wellbeing Questionnaire (Academic and School \\
& Connectedness subscales) \\
& Physical health self-rating \\
& Overall estimated grade percentage \\
& Academic probation/suspension \\
Section II-academic success & Programme retention \\
Timing and frequency of access and seeking of university support services/help- \\
section III-utilisation of mental health \\
support services & $\begin{array}{l}\text { Health Survey-Mental Health) } \\
\text { Perceived barriers to care }\end{array}$ \\
\hline
\end{tabular}

depression, ${ }^{33}$ student life satisfaction ${ }^{38}$ and emotional well-being. ${ }^{39}$ Academic success was defined both in terms of self-reported average grade percentage, any occurrence of expected academic probation or suspension, and retention (ie, plans to return to university the next year). For those students providing informed consent, actual course grades will be provided through linking survey student numbers to the university academic database (eg, grade point average (GPA) for term 1, term 2 and cumulative). Students' help-seeking and use of university health and wellness services was measured by asking students to indicate from a defined list which campus mental health services they accessed over the year. Students attempting to access services also completed measures on perceived barriers to care ${ }^{40} 41$ while timing, frequency and satisfaction of service utilisation was assessed through items from the service utilisation section of the Canadian Community Health Survey-Mental Health. ${ }^{42}$ Students were also offered the opportunity to explain in free text any barriers they encountered in accessing indicated university services, how helpful they found these services, and for suggestions as to any additional services they feel should be provided that are not (see table 2 for measure information).

\section{Data linkage}

The survey response records were linked to administrative and academic data through the unique student numbers allowing us the novel opportunity to examine the association between perceived and actual academic performance. Academic outcome data in this study include: course grades, overall grade percentage, rate of failed courses and any instance of academic probation or suspension. Authorised university administrators through the Office of Research and Institutional Planning provide the research team with the pre-specified outcome variables (as per Health Sciences and Affiliated Teaching Hospitals Research Ethics Board (HSREB) approved protocol) in encrypted files for analysis. Procedures in compliance with the Queen's University HSREB guidelines were in place to ensure data security and protection (ie, https://www.queensu.ca/secretariat/policies/ senate/electronic-information-security-policy-framework/electronic-information-security).

\section{Analytic plan}

Different mixed effects regression-based models will be used to determine the contribution of candidate risk and protective factors to well-being and academic success while accounting for clustering where appropriate. Primary outcomes include clinically significant mental health symptoms at follow-up as measured by clinical rating scales (ie, GADS-7, PHQ-9, suicide-related thoughts and behaviours) and academic grades. Secondary outcomes include life satisfaction and well-being at follow-up and any new or recurrent mental health diagnosis between baseline and follow-up. Specifically, we will examine whether different domains (personal, environmental of family) at baseline predict a change in mental health symptoms from baseline to end of first-year follow-up, predict the new onset or recurrence of a mental health condition between baseline and follow-up, predict level of life satisfaction and school-related well-being and academic outcomes. Self-reported outcome data on wellbeing and academic success at follow-up will be quantified as continuous total scores and binary outcomes where mental health diagnoses are used, and when using clinical cut-off scores of clinical symptom scales (eg, GADS-7, PHQ-9).

Administrative data on academic outcomes (eg, GPA) will be treated as continuous. Because of clustering of students within school programme, we will use generalised linear mixed models, which can be used for continuous or categorical outcomes. Potential confounders (eg, age) have been identified a priori from the literature and included in the survey. From this set of pre-identified 
variables, we will test for confounding through estimating associations of these factors with both the exposure and outcome and will adjust for in multivariable models where appropriate. Missing responses on survey questions will be dealt with through multiple imputation where only one item is missing. If more than one item is missing, complete case series analyses will be used. Characteristics of item study non-participation and item non-response will be explored to test for potential selection biases to determine the influence on effect estimates of primary associations. Access to basic socio-demographic data is available through Queen's University allowing the testing of selection biases associated with non-response. Sensitivity analyses will be conducted to determine whether non-response is associated with key factors associated with the outcome. Factors identified will be statistically adjusted for in multivariable models where appropriate.

We outline sample size requirements for a binary and continuous outcome. Binary response, sample size depends on the probability of success with larger sample sizes required for probabilities closer to 0 or 1 . As an example of a binary outcome (eg, past year prevalence of suicide attempts), in order to detect a difference (eg, between men and women) as small as 0.2 and an alpha level of 0.05 we would have $>90 \%$ power with our total sample size at follow-up $(\mathrm{n}=1984)$. Similarly, for a continuous outcome (eg, mean PHQ-9 score) and $66 \%$ of the sample being female, we will be able to detect a mean difference as small as 0.2 between females and males on the PHQ-9 with $>90 \%$ statistical power with our total follow-up sample size of 1984 (https://www.openepi. com/Menu/OE_Menu.htm).

\section{Ethics and dissemination}

Participants were provided with a Letter of Information at the beginning of the electronic survey sent via students' emails. Students provided implicit digital consent having read the letter of intent and then completed the survey. Students were encouraged by PHEs during engagement events to ask any questions they might have. The consent form details that any information provided in the survey will be kept confidential. To help ensure confidentiality, the participants are made aware that their responses will be de-identified and given a unique alphanumerical study identifier for analysis. Participants are asked to consent to having their survey data linked to their university held administrative and academic data and were assured these data will be kept strictly confidential by the research team. The Qualtrics survey platform ensures that responses are secure sockets layer encrypted and access to Qualtrics survey accounts by authorised research team personnel are single sign-on/password protected. Some of the survey items are of a sensitive nature (eg, suicide-related behaviour). Students are informed of this at the beginning of the survey in the letter of intent and are provided with a list of university support services contacts (eg, crisis line).
We will mount a national and international effort to fast-track the dissemination and translation of research findings through Editorials and Opinion pieces in newspapers, presenting at national and international conferences and generating peer-reviewed publications. An important part of the knowledge translation effort will both target and involve students through the inclusion of our PHEs in these activities. Findings will be shared with students and other stakeholders through studentdriven support and advocacy groups (Jack.org), newsletters and social media. Findings will also be shared with Best Practices in Canadian Higher Education (https:// bp-net.ca/).

\section{DISCUSSION}

More young people are entering university and the ratio of foreign to domestic students is increasing. This translates into a sizeable population of emergent adult students from different backgrounds and with highly variable risk profiles and mental health needs. There is limited data to inform universities about how best to support this growing and diverse student population. The anticipated impact from this study is to inform the development of evidence-based targeted mental health prevention and early intervention initiatives for the undergraduate student population. The long-term goal of this longitudinal survey is to form the basis of a national and international multidisciplinary programme of student mental health research to continue development and improve outcomes for students moving forward. Specifically, these data will enable us to characterise both risk and resiliency pathways and accurately estimate mental health needs of university students. Future research stemming from this work will include the mapping of transitions to student mental health services and the development of informative quality of care indicators. A model of proactive student mental healthcare across the spectrum of need with embedded standardised metrics for evaluation and further development will then be possible.

\section{Author affiliations}

${ }^{1}$ Psychiatry, University of Oxford, Oxford, UK

${ }^{2}$ Queens University, Kingston, Ontario, Canada

${ }^{3}$ Public Health Sciences, Queen's University, Kingston, Ontario, Canada

${ }^{4}$ Psychology, Queens University, Kingston, Ontario, Canada

${ }^{5}$ Dalla Lana School of Public Health, University of Toronto, Toronto, Ontario, Canada

${ }^{6}$ Mathematics and Statistics, Guelph, Ontario, Canada

${ }^{7}$ University of Ottawa, Ottawa, Ontario, Canada

${ }^{8}$ University of Oxford, Oxford, UK

${ }^{9}$ Psychiatry, Queen's University, Kingston, Ontario, Canada

Acknowledgements We would like to thank the students and faculty who participated in the engagement campaign of the U-Flourish survey contributing to a very successful response rate. We would also like to thank Roz Murphy for her help with graphics and the students for their participation in this research. Anne Duffy is a Visiting Fellow at All Souls College, University of Oxford for the 2019-2020 academic year supporting the launch of the U-Flourish research at the University of Oxford.

Contributors $A D$ is the principal investigator leading the U-Flourish research and collaboration with all authors (SMG, DR, HF, NK, MM, CDGK-S, JH, ET, CRB, WP, KH, 
$\mathrm{KES}, \mathrm{SC}, \mathrm{SMCN}) . \mathrm{AD}$ led the conception and design of this research project. NK, WP, JH, SG and CK developed the statistical plan, HF and DR, student peer health educators, planned and conducted the engagement campaign with support from $A D, S M c N$, and CRB. NK and MM led survey development in qualtrics and launch. $S G$ together with $A D$ drafted the current manuscript and DR and ET assisted in editing. All authors contributed to the final editing and approved the content of the submitted manuscript.

Funding This works was funded by a Canadian Institutes for Health Research Strategy for Patient-Oriented Research Grant (\#397428) with matched funding from the Rossy Family Foundation (https://artwithimpact.org/partner/ the-rossy-family-foundation/).

\section{Competing interests None declared.}

Ethics approval Ethical approval was obtained by the Health Sciences and Affiliated Teaching Hospitals Research Ethics Board (HSREB) (\#6023126) at Queen's University.

Provenance and peer review Not commissioned; externally peer reviewed.

Open access This is an open access article distributed in accordance with the Creative Commons Attribution Non Commercial (CC BY-NC 4.0) license, which permits others to distribute, remix, adapt, build upon this work non-commercially, and license their derivative works on different terms, provided the original work is properly cited, appropriate credit is given, any changes made indicated, and the use is non-commercial. See: http://creativecommons.org/licenses/by-nc/4.0/.

\section{REFERENCES}

1. Paus T, Keshavan M, Giedd JN. Why do many psychiatric disorders emerge during adolescence? Nat Rev Neurosci 2008;9:947-57.

2. Findlay L. Depression and suicidal ideation among Canadians aged 15 to 24. Health Reports Findlay L 2017;28.

3. Kessler RC, Amminger GP, Aguilar-Gaxiola S, et al. Age of onset of mental disorders: a review of recent literature. Curr Opin Psychiatry 2007;20:359-64.

4. Cunningham S, Duffy A. Investing in our future: importance of postsecondary student mental health research. Can J Psychiatry 2019:1-11.

5. Universities Canada. Universities Canada estimates, 2017.

6. Trends in Higher Education. 2011. Ottawa, ON, The Association of Universities and Colleges of Canada.

7. National College Health Assessment, 2016. retrieved 24 Oct 2017, from. Available: www.queens.ca/studentaffairs/health-and-wellness/ ncha-student-health-and-wellness-survey

8. HBSC, 2011 retrieved October 24th, 2017 from. Available: https:// www.canada.ca/en/public-health/services/health-promotion/ childhood-adolescence/programs-initiatives/school-health/healthbehaviour-school-aged-children/hbsc-publications-resources/healthcanada-young-people-mental-health-focus-2011.html

9. Sullivan PF, Agrawal A, Bulik CM, et al. Psychiatric genomics: an update and an agenda. Am J Psychiatry 2017. appiajp201717030283.

10. Duffy A, Grof P, Robertson C, et al. The implications of genetics studies of major mood disorders for clinical practice. J Clin Psychiatry 2000;61:630-7. and.

11. Petronis A. Epigenetics as a unifying principle in the aetiology of complex traits and diseases. Nature 2010;465:721-7.

12. Harkness KL, Bagby RM, Stewart JG, et al. Childhood emotional and sexual maltreatment moderate the relation of the serotonin transporter gene to stress generation. J Abnorm Psychol 2015;124:275-87.

13. Varese F, Smeets F, Drukker M, et al. Childhood adversities increase the risk of psychosis: a meta-analysis of patient-control, prospectiveand cross-sectional cohort studies. Schizophr Bull 2012;38:661-71.

14. Khaleque A. Perceived parental warmth, and children's psychological adjustment, and personality dispositions: A meta-analysis. J Child Fam Stud 2013;22:297-306.

15. Brouwer J, Jansen E, Hofman A, et al. Early tracking or finally leaving? determinants of early study success in first-year university students. Research in Post-Compulsory Education 2016;21:376-93.

16. Adams DR, Meyers SA, Beidas RS. The relationship between financial strain, perceived stress, psychological symptoms, and academic and social integration in undergraduate students. J Am Coll Health 2016;64:362-70.

17. Andrews $B$, Wilding JM. The relation of depression and anxiety to life-stress and achievement in students. Br J Psychol 2004;95:509-21.

18. Hurst CS, Baranik LE, Daniel F. College student stressors: a review of the qualitative research. Stress Health 2013;29:275-85.

19. Rahmani P. The relationship between self-esteem. achievement goals and academic achievement among the primary school students Social and Behavioural Sciences 2011;29:803-8.

20. Walker LS, Greene JW. The social context of adolescent self-esteem. $J$ Youth Adolesc 1986;15:315-22.

21. Haslam SA, Jetten J, Postmes T, et al. Social identity, health and Well-Being: an emerging agenda for applied psychology. Appl Psychol 2009;58:1-23.

22. Jetten J, Haslam C, Alexander SH. The social cure: Identity, health and well-being. Newy York: Psychological Press, 2012.

23. Doménech-Betoret F, Gómez-Artiga A, Lloret-Segura S. Personal variables, motivation and avoidance learning strategies in undergraduate students. Learn Individ Differ 2014:35:122-9.

24. Doménech-Betoret $F$, Abellán-Roselló L, Gómez-Artiga A. SelfEfficacy, satisfaction, and academic achievement: the mediator role of students' expectancy-value beliefs. Front Psychol 2017;8:1-12.

25. Zimmerman BJ. Self-regulating academic learning and achievement: the emergence of a social cognitive perspective. Educ Psychol Rev 1990;2:173-201.

26. Curcio G. Ferrara M and de Gennaro L. sleep loss, learning capacity and academic performance. Sleep Med Rev 2006;10:323-37.

27. Qualtrics. Provo, Utah, USA: Qualtrics, 2018.

28. Rosenberg M. Society and the adolescent self-image. Princeton University Press: Princeton, NJ, 1965.

29. Perris $\mathrm{C}$, Jacobsson L, Lindström $\mathrm{H}$, et al. Development of a new inventory assessing memories of parental rearing behaviour. Acta Psychiatr Scand 1980;61:265-74.

30. Hjemdal O, Friborg O, Stiles TC, et al. And JH. R. A new scale for adolescent resilience: grasping the central protective resources behind healthy development. Measuring and Evaluation in Counseling and Development 2006;39:84-96.

31. Bifulco A, Brown GW, Harris TO. Childhood experience of care and abuse (CECA): a retrospective interview measure. $J$ Child Psychol Psychiatry 1994;35:1419-35.

32. Spitzer RL, Kroenke K, Williams JBW, et al. A brief measure for assessing generalized anxiety disorder: the GAD-7. Arch Intern Med 2006;166:1092-7.

33. Kroenke K, Spitzer RL, Williams JB. The PHQ-9: validity of a brief depression severity measure. J Gen Intern Med 2001;16:606-13.

34. Posner K, Brown GK, Stanley B, et al. The Columbia-Suicide severity rating scale: initial validity and internal consistency findings from three multisite studies with adolescents and adults. AJP 2011;168:1266-77.

35. Nolte $\mathrm{H}$, Weischer $\mathrm{C}$, Wilkesmann $\mathrm{U}$, et al. Tegethoff $\mathrm{Hg}$ Kontrolleinstellungen zum Leben und Zur Zukunft. Auswertung eines neuen, sozialpsychologischen Itemblocks Im Soziooekonomischen panel. Diskussionspapiere aus der Fakultaet für Sozialwissenschaft: Ruhr-Universität Bochum, 1997.

36. Pintrich PR, Smith DA, Garcia T, et al. A Manual for the Use of the Motivated Strategies for Learning Questionnaire (MSLQ). Ann Arbour, MI: National Center for Research to Improve Postsecondary Teaching and Learning, 1991.

37. Espie CA, Kyle SD, Hames P, et al. The sleep condition indicator: a clinical screening tool to evaluate insomnia disorder. BMJ Open 2014;4:e004183.

38. Zullig KJ, Huebner ES, Patton JM, et al. The brief multidimensional students' life satisfaction scale-college version. Am J Health Behav 2009;33:483-93.

39. Renshaw TL, Bolognino SJ. The College Student Subjective Wellbeing Questionnaire: A Brief, Multidimensional Measure of Undergraduate's Covitality. J Happiness Stud 2016;17:463-84.

40. Clement S, Brohan E, Jeffery D, et al. Development and psychometric properties the barriers to access to care evaluation scale (BACE) related to people with mental ill health. BMC Psychiatry 2012;12:36.

41. Vanheusden K, Mulder CL, van der Ende J, van Lenthe FJ, et al. Young adults face major barriers to seeking help from mental health services. Patient Educ Couns 2008;73:97-104.

42. Gravel R, Béland $Y$. The Canadian community health survey: mental health and well-being. Can J Psychiatry 2005;50:573-9. 